\title{
FIELD GUIDE TO
}

WILD MUSHROOMS OF PENNSYLVANIA AND THE MID-ATLANTIC 


\section{FIELD GUIDE TO}

\section{Wild Mushrooms}

of Pennsylvania AND THE MID-ATLANTIC

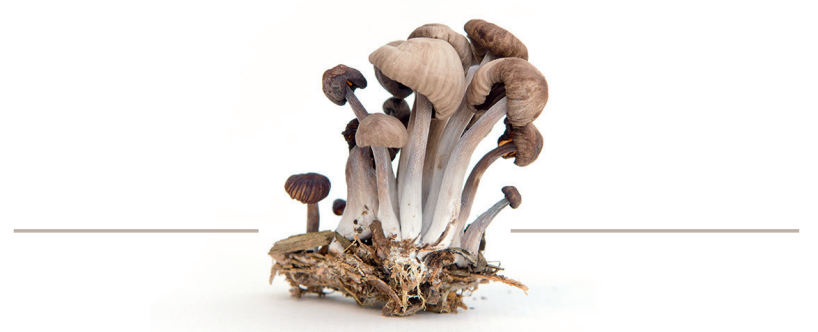

Revised and Expanded Edition

BII I R U S S I I

The Pennsylvania State University Press

University Park, Pennsylvania 


\section{$\sqrt{k}$}

\section{A KEYSTONE BOOK ${ }^{\circledR}$}

Keystone Books are intended to serve the citizens of Pennsylvania. They are accessible, well-researched explorations into the history, culture, society, and environment of the Keystone State as part of the Middle Atlantic region.

Unless otherwise noted, all photographs are the author's own. Photographs on pages iii, vi, and 23 by Darren Andrew Weimert.

Library of Congress Cataloging-in-Publication Data

Names: Russell, Bill, 1935- , author.

Title: Field guide to wild mushrooms of Pennsylvania and the Mid-Atlantic / Bill Russell.

Description: Revised and expanded edition. | University Park, Pennsylvania : The Pennsylvania State University Press, [2017] | “A Keystone book.” | Includes bibliographical references and index.

Summary: "A revised and expanded field guide providing descriptions and photographs of one hundred and twenty-five types of mushrooms, including details such as their scientific and common names, diagnostic features, size and color, edibility, primary habitats, similar species, and information from recent scientific studies"-Provided by publisher.

Identifiers: LCCN 2016057638 | ISBN 9780271077802 (pbk. : alk. paper)

Subjects: LCSH: Mushrooms-PennsylvaniaIdentification. | Mushrooms-Middle Atlantic States-Identification.

Classification: LCC QK605.5.P4 R87 2017 | DDC $579.609748-\mathrm{dc2} 3$

LC record available at https://lccn.loc.gov/2016057638

Copyright (c) 2017 The Pennsylvania State University All rights reserved

Printed in China

Published by The Pennsylvania State University Press, University Park, PA 16802-1003

The Pennsylvania State University Press is a member of the Association of American University Presses.

It is the policy of The Pennsylvania State University Press to use acid-free paper. Publications on uncoated stock satisfy the minimum requirements of American National Standard for Information Sciences-Permanence of Paper for Printed Library Material, ANsI Z39.48-1992. 